\title{
EL PENSAMIENTO MARXISTA EN LA CRISIS DE LOS MOVIMIENTOS DE EMANCIPACION
}

\author{
Francisco Fernández Buey *
}

Intentemos, primero, ponernos de acuerdo sobre qué entender por marxismo. E intentémoslo tratando de respetar al mismo tiempo un par de preocupaciones compartidas por la gran mayoría de las personas que se han ocupado de este asunto con distancia críti$\mathrm{ca}$, independientemente de que fueran marxistas o no. Primera preocupación: que no hay que quedarse en discusiones nominalistas, en discusiones sobre palabras, en estos tiempos difíciles en los que los principales conceptos de la teoría de la liberación tienen que ser repensados. $Y$ segunda: que al tener tanto que ver, como tienen que ver, las grandes palabras con las creencias fuertemente arraigadas entre los partidarios de la emancipación, y estas creencias con el tipo de identidad cultural que configura una tradición (como la socialista marxista), no es bueno dejar que estas palabras nuestras se prostituyan, las prostituyan, para lanzarlas después por la borda y quién sabe si acabar diciendo con una nueva palabra, unas cuantas décadas después, algo muy parecido a lo que se decía con la antigua palabra.

\footnotetext{
- Profesor visitate de la UCA.
} 
Así pues, frente a las persistentes añoranzas habría que evitar el echar mano de la vieja palabra cuando falta el concepto, las ideas. Y frente a las inevitables "moderneces" habría que recordar que en nuestro mundo de hoy la pérdida de la palabra equivale a lo que para los indios americanos era la pérdida de sus dioses.

A los efectos de la discusión que ahora importa se puede empezar describiendo el marxismo de Marx como un cuerpo teórico unitario conformado al menos por: l) un filosofar asistemático, polémico, de raíz humanista y materialista y, en tal sentido, crítico (crítico no sólo de la especulación apriorista, sino también de las ideologías, de la falsa conciencia); 2) un análisis económico-sociológico e histórico del modo de producir y de algunos rasgos sustanciales de las principales formas de vida en el capitalismo; y 3) una teoría de la revolución centrada en la idea de que los grupos sociales no renuncian gratuitamente a sus privilegios, pero centrada también en la estimación de los factores que juegan, o pueden jugar, a favor del tránsito de la sociedad capitalista a la sociedad comunista, y orientada, la teoría, por una elección de valores entre los cuales los más salientes son: la emancipación del género humano, la igualdad social y el desarrollo omnilateral de las capacidades sentimentales y racionales del ser humano

Si uno se atiene a lo que ha sido la historia de la filosofía, de la economía y de la teoría política hasta el siglo XIX puede concluir con razón que, tomados por separado, cada uno de estos rasgos o características del marxismo tiene antecedentes conocidos. No es cosa de negar tampoco que, en esa historia, ha habido filósofos materialistas más sistemáticos y tal vez más interesantes que Marx; economistas más precisos en la conceptualización y mejor preparados para el cálculo formal; y teóricos de la política e historiadores más cultos y quizá igual de agudos que él.

La verdadera novedad que aporta el marxismo a la historia del pensamiento es precisamente esta ocurrencia consistente en juntar el análisis económico-sociológico con un filosofar a la vez dialéctico (lo que en este contexto se puede traducir por: histórico concreto), inmanentista (o sea, materialista), y puesto, además, al servicio de los explotados y oprimidos del mundo. Pues se trata de una forma de ver las cosas - la naturaleza, el individuo humano, la socie- 
dad- que pretende hacer compatibles la crítica radical de lo existente bajo el capitalismo (crítica, en particular, de las ideologías de las clases sociales dominantes), con la intención científica y con la afirmación explícita de los valores morales de partida, o sea, del ideal que puso en marcha tanto la crítica como la aspiración al conocimiento racional de lo que hay socialmente. Sin duda fue esto, esta ocurrencia notable, lo que dió al marxismo la fuerza de una creencia para sectores muy amplios de las poblaciones europeas durante décadas.

Discutiremos luego, porque vale la pena discutirlo, hasta qué punto este rasgo diferenciador del marxismo (su vocación científica y globalizadora mediada por la crítica) fue realmente un logro histórico o sólo una sana intención, y si tal vocación constituye o no una temeridad desde los puntos de vista epistemológico o metodológico y político-moral. Ahora interesa precisar un poco más acerca de la sustancia del marxismo.

En mi opinión, el marxismo ha sido ante todo pensamiento de la liberación humana, teoría de la revolución social. Como pensamiento de la liberación humana, el marxismo prolonga y afina una tradición milenaria; como teoría de la revolución social, sitúa en una fase nueva la vieja lucha de los parias de la tierra por emanciparse en esta tierra.

El marxismo es heredero de la Ilustrąción. Pero también heredero del romanticismo y de la pasión liberadora (prometeica, espartaquista y münzeriana) de los de abajo, sean éstos esclavos, siervos o proletarios industriales. Las dos herencias, la ilustrada y la romántico-revolucionaria, estaban ya en el joven Marx. Y con matices y alteraciones que no son del caso aquí, estas dos herencias las reencontramos en el viejo Marx, quien, en los diez últimos años de su vida, se vió obligado por las circunstancias a repensar la teoría de la historia contenida en el volumen primero de $E l$ capital.

Se puede hablar de teoría de la revolución social justamente en la medida en que el marxismo eleva el antiquísimo sueño de los 
esclavos, de los siervos y de los proletarios de este mundo tanto en el plano del conocimiento como en el plano de la organización, de la práctica organizada. En el plano del conocimiento, mediante el análisis de la interacción de los factores económicos, sociales y culturales que bajo el capitalismo hacen del hombre una mercancía y contribuyen a su alienación. En el plano de la práctica, mediante una propuesta específica de organización tendente a transformar la sociedad. El socialismo de raíz marxista quiere ser expresión de la pasión razonada de los parias de la tierra.

Hay unas cuantas tesis características del marxismo de Marx, y relacionadas con esta tentativa de sintesis, que querría volver a recordar aquí para analizar más tarde si aún pueden dar algo de sí.

La primera viene a decir que aunque el capitalismo ha creado por primera vez en la historia la base técnica para la liberación de los humanos, no obstante ello, por su lógica interna, este sistema amenaza con transformar las fuerzas de producción en fuerzas de destrucción.

La segunda concreta un poco más esta transformación de las fuerzas productivas en fuerzas destructivas para afirmar taxativamente que el desarrollo del capitalismo, además de liquidar los últimos velos del sentimentalismo, mina las fuerzas de toda riqueza, o sea, no sólo el trabajo humano sino también el medio natural, la naturaleza.

La tercera tesis precisa que la causa principal de esta amenaza que transforma las fuerzas de producción en fuerzas destructivas y que mina las fuentes de toda riqueza es la lógica del beneficio privado, con su tendencia a valorar todo, o casi todo, en dinero. En todo capitalismo, desde sus orígenes, hay una contraposición entre "racionalidad" económico-crematística parcial e irracionalidad socio-económica global. La mundialización del capitalismo, su tendencia a convertirse en sistema mundial, puede atenuar la percepción del carácter parcial de su racionalidad, por ejemplo, en el centro del mismo sistema, pero no puede anular aquella contraposición: su irracionalidad resalta tanto más en la plétora miserable, donde el despilfarro más absoluto compite con el hambre y la miseria de millones de niños, mujeres y varones. 
La cuarta tesis dice así: el carácter ambivalente del progreso técnico se acentúa en el capitalismo de tal manera que obnubila la conciencia de los hombres, aliena al trabajador en primera instancia y a toda la especie por derivación. Es esta obnubilación de la conciencia lo que está detrás de la cristalización repetitiva de las formas ideológicas de la cultura burguesa, en particular de dos de sus formas: la legitimación positivista de lo dado, de lo que hay, de lo existente, y la añoranza romántica de un pasado idealizado.

Por último, el marxismo de Marx postula que, para acabar con la noria de las ideas que representa esta repetición exasperante de positivismo y romanticismo, hay que ir perfilando una nueva cultura alternativa, parte importante de la cual es la crítica de las ideologías, incluyendo la crítica de la política. Pero el cambio de sistema que esto supone no requiere sólo crear un poder nuevo, una nueva forma de dominación con el signo clasista invertido (la revolución política y social), sino también, y sobre todo, perfilar y experimentar, avanzar e inventar hábitos, costumbres y modos de comportamiento alternativos en todos los órdenes de la vida. Esta transformación cultural sólo puede llevarse a cabo por contacto o interacción con las puntas más elaboradas del saber a las que llamamos ciencias, las cuales son por lo general externas a la subcultura obrera. De ahí la necesidad de una aproximación histórica entre ciencia y proletariado.

Dicho eso hay que atender en seguida a una diferenciación que muchas veces se pierde en las discusiones, a saber: que marxismo (en tanto que cuerpo teórico desarrollado por Marx y otros) y socialismo (en tanto que movimiento u organización sociopolítica creada para lograr el fin de la sociedad regulada, de la sociedad de iguales) no son términos equivalentes. El marxismo pretende ser la ciencia del socialismo, pretende dar carácter científico a la viejísima aspiración al socialismo, o sea, a la igualación social y a la sociedad regulada racionalmente, de una parte de la humanidad. $\mathrm{E}$ independientemente de lo que pueda opinarse hoy de tal pretensión, lo cierto es que no todo socialismo (en la medida en que con esta palabra hacemos referencia a un movimiento o a un partido) ha tenido raiz marxista. Antes y después de Marx ha ha- 
bido otros socialismos. Basta con recordar a este respecto el apartado con el que termina el Manifiesto comunista y la persistencia a lo largo del tiempo de organizaciones socialistas basadas en ideas de Fourier, de Cabet, de Owen, de Saint-Simon, de Babeuf o de Blanqui, por citar sólo a otros cuantos clásicos del socialismo. Varios socialismos de orientación religiosa han seguido existiendo en Europa, América, Asia y Africa durante la segunda mitad del siglo XDX y lo que llevamos del siglo XX. Y luego está el socialismo (o comunismo) anarquista inspirado por Bakunin y por Kropotkin.

Por otra parte, tampoco todo marxista ha sido siempre y necesariamente socialista. Precisamente porque el marxismo se ha presentado a veces como una ciencia en el sentido fuerte de la palabra, se puede aceptar alguno de los elementos de la aportación marxiana en el ámbito del conocimiento crítico de las realidades económicas y sociológicas (por ejemplo, la concepción materialista de la historia como hipótesis interpretativa del pasado de los hombres, como teoría de la historia) sin aspirar por ello a una sociedad socialista, o sin decidirse a luchar por tal sociedad en el movimiento socialista organizado.

Puesto que durante cierto tiempo la vulgata marxista ha predicado la identificación sin más entre marxismo y socialismo, y como el abandono formal del marxismo por parte de muchos partidos socialistas ha dado lugar a apasionadas controversias, no suele aceptarse con facilidad la posibilidad de diferenciación. Y, sin embargo, ésta no es una conjetura inventada, sino una realidad: ya en las últimas décadas del siglo pasado existía un marxismo llamado "de cátedra" con tal orientación; y ciertas variantes del "marxismo analítico" actual podrían ser consideradas en los mismos términos. Debe reconocerse que ésta no ha sido una actitud muy extendida en la historia contemporánea del marxismo y del socialismo, pero es teóricamente posible; y se trata, además, de una posibilidad tanto más atendible a medida que algunas ideas básicas del materialismo histórico, de la concepción materialista y dialéctica de la historia, han ido pasando a los programas de enseñanza secundaria y superior de muchos países del mundo actual. ¿Hay que recordar que se puede ser ecólogo sin aceptar la forma dominante que ha tomado el ecologismo político contemporáneo, o teólogo sin ser necesariamente miembro activo de una iglesia y/o 
partidario de alguna de las religiones que han tomado forma institucional a lo largo de la historia?

En cualquier caso, y por lo que hace al pasado reciente, puede decirse sin exageración que la referencia al marxismo es obligada para entender lo que ha sido la lucha por la emancipación de los trabajadores en Europa durante la segunda mitad del siglo XIX, así como, más en general, la lucha por la liberación en casi todo el mundo durante el siglo XX. El que los sujetos activos de esas luchas históricas hayan sido derrotados, hayan fracasado o, en algún caso, hayan conducido a sus pueblos a situaciones lamentables no es razón suficiente para echar todo marxismo al basurero de la historia. No sólo es social y moralmente valioso lo que triunfa. A veces lo social y moralmente valioso es lo que cae derrotado y queda como un cabo suelto o perdido en la historia de la humanidad. La tecnopolítica no lo sabe; pero la política en su acepción originaria siempre ha tenido en cuenta tal posibilidad. Por eso en casi todas las culturas hay un altar reservado para los idealistas que, conociendo el hedor de este mundo, decidieron seguir siendo idealistas (en el plano moral). Puede ser que el laicismo cínico del final de siglo decida llevarse por delante, con los restos del marxismo decimonónico, todos los altares levantados por las culturas populares a los heroes derrotados en las luchas en favor de la igualdad, la libertad y la fraternidad. Pero es dudoso que la ausencia de distinción entre el valor de estas luchas de los abajo (tantas veces apadrinadas por los marxistas desde 1848) y lo que representó la utilización ideológica del marxismo desde el Poder (en la URSS, en China, en Cuba o en cualquier otro lugar) vaya a ser considerada algún día como un progreso moral.

Me parece que de esta forma verán las cosas también los historiadores del siglo XXI.

Ahora bien: una influencia tan enorme (tan omniabarcadora) en la resistencia anticapitalista moderna difícilmente cabe en un solo cuerpo doctrinal. Tal vez por eso desde la muerte de Marx ha habido varios marxismos. $Y$, hablando con propiedad, habría que decir que ya en vida de Marx había varios "marxismos", al menos en el sentido de que circulaban distintas interpretaciones filosófico-políbicas de sus ideas o de ideas atribuidas a él. Seguramente por esta razón, harto ya de atribuciones y de manipulaciones de 
su pensamiento, el mismo Marx dijo una vez, y no sólo por cansancio, que él no se consideraba marxista. Maximilien Rubel,un estupendo marxólogo hoy casi olvidado, ha estudiado muy bien este tema en un libro sintomáticamente titulado Marx critique du marxisme.

Estas dos observaciones que se acaban de hacer (que ha habido varios marxismos y que el propio Marx no quería tener nada que ver con alguno de ellos) deberían servir para apoyar una conclusión a la que me interesa mucho llegar ahora: hay incompatibilidad entre marxismo (en el sentido de pensamiento y acción de Marx) y dogmatismo (en el sentido de codificación única de las ideas procedentes de Marx en un solo cuerpo doctrinal). Aun suponiendo que no haya habido coherencia perfecta en el caso de Marx (¿y en qué caso?) entre declaraciones y aspiraciones teóricas de un lado y actividades político-sociales de otro, ¿no es paradójica la conversión en dogma de la obra de un hombre que tuvo por máxima hay que dudar de todo?

Lo interesante para el historiador de las ideas, y no sólo para él sino también para toda persona que quiera ocuparse, con comprensión simpatética, de la tragedia que siempre ha sido la lucha de los humanos por emanciparse, por liberarse, por desalienarse, es tratar de dilucidar, en este caso, por qué extrañas circunstancias la vocación científico-escéptica contenida en aquella declaración de Marx - hay que dudar de todo - condujo también al dogmatismo de muchos marxistas.

\section{4}

Todos los socialismos de raiz marxista que hasta ahora han tenido éxito político-social en el mundo han sido revisionistas, en mayor o medida, de las ideas de Marx, o bien adaptaciones de aquellas ideas a circunstancias históricas que a Marx no podían ni pasársele por la imaginación. Tal es el caso del movimiento socialista que condujo a la revolución rusa de 1917. Pero también de los socialismos que condujeron a las revoluciones china, cubana y vietnamita (por hablar sólo de las más importantes). El conocimiento que Mao, Castro o Ho tuvieron de la obra de Marx al iniciarse los procesos revolucionarios en China, Cuba y Vietnam, respectiva- 
mente, era muy limitado y unilateral. Difícilmente puede compararse con el conocimiento de la obra de Marx que tuvo V.I. Lenin. $Y$ aún menos con el conocimiento de la obra de Marx que tuvieron los principales representantes del llamado marxismo occidental (Bernstein, Kaustky, Rosa Luxemburg, Korsch, Lukács, Gramsci). Esto es una verdad histórica probada. La cual verdad no quita mérito en absoluto a lo hecho por Mao, Castro o Ho. Pero obliga a estudiar con detenimiento y para cada caso concreto qué creían estar haciendo los revolucionarios cuando se referían al marxismo y qué hacían de verdad, en la realidad.

Hasta ahora esta discrepancia entre lo que se creía estar haciendo y lo que se hacía realmente sólo se ha estudiado (y aún en forma parcial) en el caso ruso.

El resultado de ese estudio, iniciado por Karl Korsch, dice lo siguiente: Marx cambió de opinión con los años sobre las posibilidades de la revolución en la atrasada Rusia y sobre la relación de esta revolución posible con la revolución en las regiones más industrializadas de Europa: Inglaterra, Francia, Alemania. Lenin intentó explicar, de manera unilateral, aquel cambio de opinión del viejo Marx con el objetivo de seguir fundando en el marxismo la teoría de la revolución rusa; Stalin prohibió literalmente la difusión de las opiniones de Marx sobre Rusia (tanto las opiniones del Marx rusófobo de los años cuarenta y cincuenta como las opiniones del Marx viejo, amigo de los narodnikis) y manipuló a conciencia el pensamiento de Marx para que la revisión leninista pareciera la sirnple continuación de aquél.

Durante algún tiempo se pensó que la hibridación de marxismo y narodnikisismo (populismo nacionalista revolucionario) fue la base teórica del éxito práctico que representó la revolución rusa del 17. Creo que puede probarse que no fue así. El híbrido marxista-populista construido por V.I. Lenin en los años que hacen de gozne entre los dos siglos estaba prácticamente muerto en 1905. La revolución de noviembre de 1917 tiene mucho más que ver con los horrores de la primera guerra mundial que con el constructo teórico (la"dictadura democrática del proletariado" inspirada en la fase jacobina de la revolución francesa) de V.I. Lenin. La grandeza político-militar de V.I. Lenin, como la de Napoleón Bonaparte, con- 
siste sobre todo en su capacidad para la captación de la excepcionalidad histórica, cuando no hay tiempo para el cálculo racional y la loa de la duda se convierte ya en preámbulo de la aniquilación. V.I. Lenin fue durante toda su vida un genio de las situaciones extremas, un agudo desvelador del sentido de las crisis históricas. En los momentos decisivos $-y$ los meses que van de febrero a noviembre de 1917 lo fueron- solía sorprender a todos los que le conocían. Pero V.I. Lenin no era un teórico en el sentido en que lo fue Marx. Esta es una diferencia que conviene tener en cuenta.

Quisiera añadir al llegar a este punto que no se puede explicar históricamente el contraste entre ideario marxista y realidad de la URSS en las primeras décadas de la revolución sin estudiar en detalle la relación de Marx con los rusos así como la recepción y difusión del marxismo en Rusia antes y después de 1917. La idea de que el estalinismo y el gulag se derivan necesariamente del ideario socialista marxista no tiene más fundamento que el intento de derivar los campos de concentación del Chile de Pinochet del Sermón de la montaña o los campos de concentración nazis de la crítica a la democracia demediada y al parasitismo de la época de Weimar. Para establecer una relación causal entre los crimenes cometidos en nombre del socialismo y el ideario de Marx no basta con tomar nota de las palabras de los criminales y ponerlas en relación con otras palabras que suenan de forma parecida; hace falta un análisis específico de la evolución y del destino de los distintos socialismos de raiz marxista que en el mundo han sido.

También fue Karl Korsch el primero en establecer un corte tajante entre "marxismo occidental" y "marxismo ruso", atribuyendo precisamente las degeneraciones de este último a las concesiones que Marx, siendo ya viejo, hiciera a los populistas (narodnikis) de aquella nacionalidad. Esta es una hipótesis historiográfica sugestiva que habría que explorar. Que Marx hizo concesiones a los populistas rusos de la década de los setenta del siglo pasado está fuera de toda duda razonable. No se suele decir en ambientes marxistas que estas concesiones fueron la contrapartida del acercamiento a Marx y al internacionalismo obrero de la época por parte del populismo revolucionario ruso (en sus orígenes principalmente nacionalista) contra la opinión de los marxistas rusos. 
Ya este dato debería ser materia de reflexión para todos aquellos ideólogos que siguen repitiendo, contra los hechos, que Karl Marx pensó exclusivamente en la revolución europeo-occidental (en la revolución inglesa, francesa y alemana) y que la revolución rusa de 1917 habría sido la negación de sus previsiones históricas. La verdad es que allá para 1878 Marx había abandonado toda pretensión de hacer de su método histórico-dialéctico una filosofía de la historia o un pasaporte teórico válido para explicar cualquier desarrollo histórico. Desconfiaba mucho de ls principales dirigentes socialistas alemanes, ingleses y franceses, y lo que se proponía, mientras tanto, era algo bastante modesto: conocer mejor la evolución de los acontecimientos económico-sociales en EEUU de Norteamérica y en Rusia. Tanto es así que hizo a un lado el material acumulado para la publicación del segundo volumen de El Capital y, a pesar de los años y de los achaques, se puso,una vez más, a estudiar: ruso por una parte y estadísticas de actualidad, norteamericanas, inglesas y rusas, por otra. Sólo que las gentes apasionadas por la revolución - y Marx era uno de ellos- no dejan de acoger con entusiasmo ni cuando estudian las buenas nuevas en los tiempos sombríos. $Y$ la buena nueva de los últimos años de vida de Marx fue precisamente el surgimiento del movimiento revolucionario en el hogar clásico del absolutismo, en la Rusia zarista, justo cuando decaía el espíritu revolucionario en el otro lado de Europa, en los hogares clásicos del capitalismo (como consecuencia, entre otras cosas, de la derrota de la Commune en París).

Pues bien: desde el punto de vista historiográfico, el problema interesante consiste en aclarar si Marx prefirió la valentía moral de aquellos hombres y mujeres (revolucionarios "terroristas"), que se atrevían a luchar contra el absolutismo zarista, a las vacilaciones de los principales destacamentos del proletariado industrial europeo-occidental (francés, alemán e inglés, sobre todo), por acentuación del propio voluntarismo revolucionario, por el disgusto que acompaña al malestar de la cultura, o si, por el contrario, en la eventual revolución rusa que los narodnikis anunciaban como inevitable él vió sólo un complemento para la revolución europeo-occidental.

Las dudas y vacilaciones que ponen de manifiesto los borrado- 
res de la célebre carta a Vera Zasulich (febrero/marzo de 1881) permiten sugerir que el viejo Marx no llegó nunca a resolver ese dilema. Al menos con la cabeza; pues sabemos, en cambio, por la correspondencia de la época, que su corazón estaba con los populistas (aunque éstos no eran "marxistas" típicos u ortodoxos). Pero ni siquiera esto último puede aducirse como prueba de la existencia de un vínculo entre marxismo y estalinismo (entre el "terrorismo" populista-marxista de los 80 del siglo pasado y el "terrorismo" del estado estalinista), puesto que en los cuarenta y tantos años transcurridos entre ambas cosas la historia hizo casi irreconocibles a los antiguos marxistas y a los antiguos populistas rusos. Tanto que una buena parte de los social-revolucionarios que recogieron la herencia de los narodnikis fueron asesinados, bajo Lenin y bajo Stalin, por marxistas que recogían la herencia de Marx. Establecer relaciones causales tomando como base la semejanza de las siglas o el parecido de las palabras, sin fijarse en los hechos, es un cómodo expediente simplificador de la historia que el partidismo político conservador usa en beneficio propio a poco que el adversario ideológico prefiera también la ambigüedad.

\section{5}

Atendiendo a las diferencias entre el marxismo de Marx y el de Lenin, así como a la evidente degradación del marxismo que representó el estalinista "socialismo en un solo país", y sin llegar a resolver, por otra parte, el interesantísimo problema planteado por Karl Korsch, hace tiempo ya que se hizo habitual distinguir entre "marxismo ruso" y "marxismo occidental". El denominado "marxismo occidental" es, en efecto, uno de los marxismos históricamente existentes. Se le podría considerar como un marxismo trágico: es el marxismo de los revolucionarios sin revolución; el mejor de los marxismos que ha habido hasta ahora desde el punto de vista de la teoría, de la explicación de los hechos que han tenido que ver con las revoluciones y de las previsiones autocríticas del movimiento obrero, pero, pese a ello, el más duramente derrotado en las batallas político-sociales que tuvieron lugar desde la primera guerra mundial en adelante. 
Rosa Luxemburg, Karl Korsch, Antonio Gramsci, Georg Lukács, los marxistas austríacos y muchos otros menos conocidos que estos han aportado grandes cosas al conocimiento de un mundo en el que, en parte, todavía vivimos; $y$, sobre todo, han contribuido de manera muy seria a fundamentar la ética de la resistencia anticapitalista en circunstancias sumamente difíciles. Ellos fueron críticos de las dos principales corrientes en que se dividió el movimiento socialista de este siglo; fueron víctimas de esa división en la que inicialmente participaron; fueron - salvando las distancias personales- combatientes derrotados ante todo y sobre todo por la reacción conservadora que invadió Europa al acabar la priemra gran guerra. Este es el marxismo de la lucidez. Pero también el marxismo de las luces limitadas a Europa. Y no necesariamente por etnocentrismo, o no siempre por etnocentrismo; en la mayoría de los casos por ignorancia, por desconocimiento de otros mundos, de otros contientes de los cuales Marx sólo había escrito en relación con (y en función de) Europa.

Esta limitación, la etnocentrista, es una limitación importante que toda tentativa actual de repensar el vínculo entre tradición y renovación en el marco de la cultura socialista tiene que tener en cuenta.

6

El "marxismo occidental" no ha sido el único marxismo interesante desde el punto de vista teórico-práctico. En este momento histórico de afirmación absolutista del occidentalismo euroamericano vale la pena recordarlo de nuevo. Para los tiempos que vendrán sigue habiendo muchas cosas notables que aprender en la ingente obra política de V.I. Lenin, sobre todo en la obra escrita antes de que la guerra y el destino hicieran de él, que por un tiempo pensó que llegaría a ver la revolución, un estadista (Lenin fue un teórico de la política cosmopolita como pocos, aunque, por desgracia, siempre citado de forma ritual, y muy poco leído con espíritu histórico-crítico, como se lee a los clásicos del pensamiento político).

Sigue habiendo muchas cosas notables que aprender en la obra de Trotski, aquel interesante hombre de acción, estupendo obser- 
vador de los problemas de la vida cotidiana y agudísimo desvelador de contradicciones en el quehacer de las gentes que quieren crear un mundo nuevo; autor indispensable, tal vez, para pensar en serio lo que quiere decir revolución de la vida cotidiana más allá de los clichés y de las frases hechas por comodidad. Las nuevas generaciones que hayan de enfrentarse a la necesidad de las revoluciones tendrán también mucho que aprender en las reflexiones críticas de Nicolai Bujárin (el marxista ruso inquieto que tuvo la valentía de dar nombres a aquellas cosas que parecían innombrables para la ortodoxia); o en no pocos de los papeles de Mao (que enseñó a casi todos los marxistas occidentales y eurocéntricos a pensar las cosas de Oriente con categorías distintas a las acuñadas en los aledaños de París entre 1789 y 1893, o por lo menos a dudar de su aplicación universal como ganzúas que abren las puertas del conocimiento de toda sociedad); y en las intervenciones de Mariátegui (quien cruzó el marxismo europeo de la subjetividad y de la voluntad con las raices andinas de un pensamiento liberador sin el cual no se explicaría casi nada de las actuales luchas en América Latina); o en el pensamiento de $\mathrm{Ho}$ Chi Min (que es la experiencia vivida de la resistencia al colonialismo, el testimonio magnífico del espíritu de la rebelión que no hace mucho conmocionó al mundo por su valor moral y que hoy, cuando todavía apenas si florecen los árboles de Vietnam regados por el napalm norteamericano, ya no existe para nosotros porque ya no existe para nuestros medios de comunicación); o en las obras de Kwame Nkrumah (que tanto enseña sobre la tragedia que ha sido y está siendo la independencia de los países africanos, y que habrá que rescatar bajo las losas de silencio con que nuevo colonialismo cubrió una de las etapas más importantes de la lucha de los africanos por su liberación).

No, no es verdad, pues, que el comunismo marxista haya pasado por el mundo sin dejar otras huellas que las del caballo de Atila o que todo lo que él hizo vaya a ir a parar al basurero de la historia, como quieren ahora los dogmáticos del neoliberalismo y 
como parecen empezar a aceptar en el centro del Imperio muchos de los letratenientes que en otros tiempos vieron en el marxismo la ciencia social por excelencia. Sólo una visión unilateral e interesada de lo que ha sido la historia de la humanidad en los últimos cien años puede defender una idea como esa.

Dos cosas han hecho plausible en Europa una presentación tan sesgada de esta historia: la derrota que ha significado para las fuerzas partidarias de la emancipación social el final del primer intento de construcción del socialismo y la monocorde presentación de la tragedia del movimiento comunista europeo como una cadena sin fin de errores y crímenes en la que el contexto histórico desaparece por completo.

La mayoría de las reconstrucciones de la historia del movimiento y de los partidos comunistas que se ha ido imponiendo durante la última década son una inversión sin más de la unilateral e ingenua historia ortodoxa construida en los años anteriores a iniciativa de los propios protagonistas. Si el rasgo característico de la hagiografía estalinista fue justificarlo todo aludiendo al poder y a la maldad del adversario capitalista, con lo que varias generaciones de comunistas se taparon, nos tapamos, los ojos y los oidos ante cuasievidencias, lo que ahora define al enfoque de la pseudohistoriografía que se está imponiendo es volver el calcetín del revés: donde, según la hagiografía estalinista, estaban la maldad y la fuerza bruta de un adversario poderoso ahora no hay apenas nada. Se presenta la historia del socialismo realmente existente y del socialismo realmente resistente como si movimiento y partidos hubieran luchado contra fantasmas que nunca llegaron a existir o contra molinos de viento inventados por la mente calenturienta de los comunistas, por la otra maldad. $Y$ así, lo que de hecho fue una tragedia de gentes con ideales, que "no pudieron ser amistosos", que tuvieron que "dormir entre asesinos" en los tiempos sombríos del fascismo y del nacionalsocialismo se cuenta ahora sobre un transfondo vaporoso en el que la otra parte, el adversario de ayer, queda completamente difuminado y las "frentes lisas" de los insensibles de ayer elevadas al rango la inteligencia, como si la cobardía de entonces hubiera sido precisamente superior capacidad de previsión. 
Lo que más impresiona de la forma actual en que los vencedores tratan de reconstruir la historia del socialismo marxista es que se pueda presentar ésta como un encadenamiento de crímenes y errores sustancialmente motivados por una supuesta visión conspirativa de la historia cuando hoy (siempre con años de retraso) se van confirmando una tras otra las sospechas que ayer se tenían sobre la intervención de los servicios de inteligencia de la OTAN en todos aquellos países del mundo en los que algún día hubo la oportunidad de que la izquierda marxista llegara al gobierno gracias a los votos de la mayoría de la población. Jean Ziegler ha contado parte de esta historia siniestra para algunos de los países del llamado "tercer mundo". Y las revelaciones recientes sobre la intervención de los servicios secretos en Italia desde 1960 hasta 1980 superan ya lo que muchos habíamos sospechado en polémica con lo que aquí, entre nosotros, criticaban ingenuamente el "estalinismo" del PCI en los días del "caso Moro".

Todavía está por hacer una historia alternativa y distanciada de lo que ha sido el socialismo como poder y el socialismo como resistencia a la barbarie durante este siglo. Una historia cuyo concepto regulador tiene que ser la idea que inspiró a Brecht su poema "A los por nacer"; una historia en la cual se de cuenta, desde su transfondo histórico, de las razones por las cuales algunos, siendo como eran buena gente, "no pudieron ser amistosos", "miraron con impaciencia la naturaleza", "hicieron el amor sin atención" y "vivieron entre asesinos". Esbozos nacionales de esta historia existen ya en Italia, en Francia, en Inglaterra, en Alemania, gracias al esfuerzo de institutos y fundaciones vinculados a partidos, sindicatos y particulares que no han creido nunca ni en las vidas de santos ni en la generalización de la criminalidad sin causas sociales. En cualquier caso, cuando esta historia alternativa pueda hacerse (y la apertura de los archivos moscovitas de la III Internacional será sin duda un buen empujón a este respecto) se comprenderá con el equilibrio necesario por qué surgió y tuvo tanto éxito el estalinismo y qué significó realmente en la URSS y fuera de la URSS, por qué nació la NEP y por qué aquella misma NEP con la que tantos estuvieron de acuerdo no pudo dar más de sí, por qué se firmó el pacto germano-soviético y por qué pudo producirse una situación como la de Stalingrado, por qué aquel final tremen- 
do de la guerra de España y por qué la segunda guerra mundial, acontecimientos, todos ellos, que son parte de la historia todavía reciente del socialismo marxista y a la vez parte de la historia de la Europa contemporánea, en la que otras fuerzas sociales y políticas callaron en los momentos decisivos en los que tantos y tantos comunistas y socialistas eran asesinados, torturados, encarcelados y vejados por el mero hecho de serlo, de decirlo o de escribirlo. Y eso en Italia, en España, en la Francia de Vichy, en la Alemania de Hitler, en el Portugal de Salazar, en la Grecia monáquica y republicana, en tantos y tantos lugares de la Europa central y occidental. Pero también en la URSS con la excusa de la lucha por el poder.

Concluyo este punto. La principal equivocación de todos los marxismos habidos hasta ahora ha sido esta: pensar que las revoluciones ocurridas desde 1917 han sido debidas a la capacidad científico-analítica de la teoría aplicada a situaciones concretas por marxistas ortodoxos, respetuosos con los textos de Marx. La verdad histórica es lo contrario: el marxismo que ha ayudado a hacer la revolución en Rusia, en China, en Cuba, en Vietnam, en Argelia no ha sido tanto la ciencia inaugurada por Marx como su inspiración político-moral. Pruebas: el marxismo "científico" del primer volumen de El capital se convirtió pronto en teoría de la burguesía, precisamente allí donde iba a hacerse la primera revolución. La razón de eso es ahora muy obvia: la teoría de la transición del feudalismo al capitalismo contenida en el primer volumen de El capital servía para justificar en Rusia la necesidad del capitalismo como progreso frente al absolutismo zarista y a la persistencia de la servidumbre. Así que los ideólogos de la burguesía rusa culta se quedaron con el esquema científico-filosófico de $E l$ capital mientras que los revolucionarios (sobre todo los populistas de los años setenta y ochenta del siglo pasado) se fijaron particularmente en la intención moral, en la voluntad emancipatoria del marxismo para una situación particularmente atrasada y, por tanto, muy difícil, lo que les obligó a añadir fuertes dosis de voluntarismo a un concepto elaborado por Marx pensando sobre todo en países como Inglaterra, Francia y Alemania donde la industria había alcanzado ya un amplio desarrollo. 
No es extraño que el propio Marx haya dudado tanto a la hora de contestar a la revolucionaria populista Vera Zassulicht, pues el dilema que ésta le planteó (si creía posible el paso directo desde la vieja y atrasada pero en tantos sentidos solidaria comuna rural a alguna forma de comunismo) fue y ha seguido siendo el gran problema de las revoluciones realmente existentes hasta ahora. (Sería interesante estudiar en este contexto si la idea dialéctica del comunismo moderno como "negación de la negación", como sobrealzamiento del viejo comunismo primitivo luego de que la historia de la humanidad hubiera superado el esclavismo, el feudalismo y el capitalismo, surge como mero desarrollo teórico, en abstracto, de la concepción dialéctica de la historia universal, o si aparece más bien como generalización plausible del caso ruso, que, obviamente, se sale del esquema contenido en el volumen primero de $E l$ capital).

Algo parecido hay que decir acerca de la relación entre el marxismo y la revolución china: el marxismo de Mao tiene en realidad muy poco que ver con el marxismo de Marx y difiere también del marxismo de los principales teóricos rusos de los años veinte y treinta. Basta con ir a las fuentes de la polémica entre Mao, Stalin, Trotski y Bujárin para darse cuenta en seguida de dónde están las diferencias. En general los rusos pretendían explicar la historia de China desde los comienzos de este siglo con el mismo esquema leninista de las etapas de la revolución rusa inspirado en el análisis marxista de las etapas de la revolución francesa. Pero si ya hubo que retorcer las cosas ( $y$ no siempre reconociéndolo de manera explícita) al pasar del cuento de París al de Moscú y san Petersburgo resultó más que evidente que el cuento de París no podía hablar también de Pequín. Una vez más el esquema se enfrentó con la vida misma. En general los rusos se quedaron con el esquema mientras que Mao retorció por segunda vez la concepción históricodialéctica de Marx para meter en ella la historia social, militar y política de un país, el suyo, sobre el que Marx en su tiempo apenas podía saber gran cosa. Tuvo éxito en la empresa. ¿Y qué decir del castrismo y del guevarismo en la revolución cubana si no que fueron un nuevo retorcimiento de las ideas del viejo Marx para meterlas ahora en el marco de la lucha de los pueblos coloniales subdesarrollados, tan lejos ya del hogar clásico 
del capitalismo y de aquella Europa industrializada en la que pensaban los primeros internacionalistas?

\section{9}

Cuando un movimiento de emancipación se considera a sí mismo como una tradición ideal es natural que ponga preferentemente el acento en la continuidad más que en la diversidad y en la ruptura de los esquemas anteriores. Sin duda, eso es parte de su fuerza. $Y$ al hacer la historia del socialismo durante el siglo $X X$ es difícil soslayar la presencia de la fuerza de la creencia hecha tradición: han sido muchos millones de personas en Europa, Asia, Africa y América los que pensaron que el socialismo de raiz marxista iba a ser la solución a sus problemas y a sus desgracias.

Despreciar este hecho es una pedantería de especuladores acríticos que luego suelen atormentarse con retorcidas preguntas acerca del retorno de los fundamentalismos o hacer la vista gorda sobre las constantes muestras de adulación y culto a la personalidad que se repiten en el marco de la propia subcultura.

El socialismo marxista se ha considerado, efectivamente, como una tradición ideal, como el receptáculo de un conjunto de creencias sobre la sociedad hecha fuerza social en una forma-partido alternativa, en contraste con la sociedad existente (fuera ésta la democracia indirecta pero representativa propia del capitalismo europeo en los momentos de vacas gordas o la tiranía nazi-fascista o el despotismo oriental o las distintas dictaduras latinoamericanas o la todavía informe organización social que marca el paso de las tribus en tantos lugares de Africa).

Y porque se ha considerado durante décadas como una tradición ideal, ha preferido ir uniendo por guiones cada uno de los nuevos retorcimientos de la doctrina inicial que iban apareciendo a lo largo de la historia: marxismo-leninismo-pensamiento Mao Tsé Tung, marxismo-leninismo-guevarismo-castrismo, marxismo-leninismo-stalinismo o marxismo-leninismo-gramscismo, según los casos y las nacionalidades. Lo que el uso generalizado de los guiones reconoce desde el punto de vista de la consideración racional de la cosa es, sin duda, la existencia de diferencias, de discontinuidades, 
entre las ideas y opiniones de Karl Marx y las de Lenin, Stalin, Gramsci, Ho, Mao, Guevara o Castro. Pero, por otra parte, ese mismo uso habitual ha funcionado durante décadas como un símbolo de la continuidad en el marco de unas mismas creencias, como un símbolo utilizado para ocultar a los simples el lado de la discontinuidad, de las diferencias.

No es ninguna casualidad el que esta forma de enfrentarse con los sucesivos retorcimientos o revisiones del marxismo de Marx se ha haya mantenido intacta hasta que se produjo el cisma chino-soviético, momento en el cual no podía dejarse ya sin problematizar diferencias culturales que eran muy obvias pero que habían quedado subsumidas por la prioridad concedida al elemento de la continuidad.

Fue Palmiro Togliatti quien propuso en Europa acabar con la vieja costumbre de silenciar los retorcimientos inevitables bajo el guión de tumo. Lo que no quiere decir que la vieja costumbre desapareciera por completo, pues, como suele ocurrir en estos casos, lo que en principio fue una práctica nacida del hacer de la necesidad virtud se convirtio, después de'su denuncia por el nuevo marxismo laico togliatiano, en simple defensa del dogma. Pero, en cualquier caso, no hay duda de que ha sido el policentrismo togliattiano, su idea de la unidad en la diversidad, lo que ha abierto el camino a una concepción laica de la tradición socialista.

Podría decirse, pues, que los marxismos del siglo $X X$ nacidos en la cuna de las revoluciones rusa, china, vietnamita y cubana han sido en gran medida recubrimientos ideológicos de una práctica en verdad revolucionaria 0 , también, criaturas híbridas concebidas por el maridaje entre algún tipo de marxismo y algún tipo de pensamiento de liberación nacional más o menos consolidado ya anteriormente ( $\sin$ forzar históricamente las cosas así puede interpretarse el leninismo - hibrido de marxismo y populismoel maoísmo - híbrido de marxismo y senyuseismo*- el castrismo -híbrido de marxismo y martinismo-, etc.

Por lo demás, una cosa así se podía prever. La ciencia social sólo podrá ser parcialmente predictiva en situaciones en las que se supone que han de interver:r colectivos muy amplios, multitudes. La grandeza del marxismo es haber juntado en un mismo corpus teórico la intención, la vocación de hacer ciencia, y la inspiración 
moral-política del espíritu de la rebelión de los de abajo. Lenin, que de todos los marxistas que han encabezado revoluciones, fue el que mejor conoció la obra de Karl Marx tuvo que hacer grandes equilibrios para explicar con categorías marxianas lo que estaba pasando y lo que iba a pasar en Rusia. Ejemplos: su concepto de revolución democrático-burguesa hecha por el proletariado industrial o su concepto de dictadura democrática del proletariado y del campesinado. Híbridos así no hubieran cabido en la cabeza de Marx, seguramente. Pero la realidad rusa era tan oceánica que tampoco cabía en los marcos de una filosofía, ni siquiera en los de una filosofía tan omnicomprensiva como estaba siendo ya la marxista. Mao, para poder llevar a término la revolución china, tuvo que fabricar una teoría de las contradicciones que con toda seguridad tiene mucho más que ver con el pensamiento filosófico chino tradicional que con la inversión marxiana de la dialéctica hegeliana. Y Castro empieza siendo un demócrata revolucionario-liberador en línea Las Casas-Martí para hacerse marxista-leninista por necesidades económico-políticas de la isla de Cuba sin haber leído antes El Capital y conociendo muy poco a Lenin.

\section{0}

En el plano epistemológico probablemente el problema principal del marxismo, visto en perspectiva, es que, por comparación con otras corrientes filosóficas o con las ciencias sociales académicamente establecidas, hace una apuesta muy fuerte: pretende a la vez explicar el mundo económico- social en que vivimos, hacer su crítica y transformarlo. Nada menos.

La mayoría de las corrientes filosóficas contemporáneas han expresado dudas sobre este proyecto o lo han considerado de imposible realización. Incluso alguna de las corrientes filosóficas contemporáneas que simpatiza con el marxismo, como la formada por los autores de la llamada Escuela de Frankfurt, se ha ido distanciando progresivamente de aquel proyecto basándose en la idea de que una cosa es la comprensión critica de la historia y la estructura del capitalismo propuesta por Marx, cosa aceptable, y otra, muy distinta, su idea de la transformación de la sociedad capitalista en un sentido revolucionario como consecuencia de la 
agudización de contradicciones denominadas "objetivas".

Otras corrientes han ido aún más lejos en la denuncia de las pretensiones analíticas, críticas y revolucionarias del marxismo clásico o tradicional. Por ejemplo, la corriente popperiana del liberalismo contemporáneo está convencida de que la pretensión analítica de Marx y de los marxistas se autodestruye por su enfoque holista o globalista, lo cual tiene que conducir necesariamente a exageraciones en la crítica de las economías de mercado y a aberraciones totalitarias en la propuesta político-moral alternativa. Con una orientación epistemológica parecida, aunque no siempre con las mismas finalidades políticas, también se ha aducido que el programa teórico marxista es excesivo porque supone la tentativa de formular una cosmovisión o concepción del mundo que es de imposible realización por razones lingüísticas o lógico-materiales.

De todas formas, frente a lo que se afirma a veces de manera interesada, hay que decir en descargo del marxismo que la suya no es la única apuesta fuerte de este tipo en la historia de la humanidad. A su manera, las grandes religiones aspiraban a lo mismo. Y modernamente algunas otras "grandes teorías" han tenido aspiraciones parecidas, aunque es posible que con un poco más de moderación epistemológica (o de retórica correctora de los antiguos excesos epistemológicos). Algunos pensamos que la especulación filosófica o metacientífica en que suele concluir casi toda gran teoría recoge, en el fondo, un anhelo semejante, históricamente cambiante en la forma pero permanente en su contenido; un anhelo muy extendido entre los humanos, que tal vez tenga que ver con los límites del análisis reductivo y el origen de la vieja idea de dialéctica.

En cualquier caso, limitarse a la explicación del mundo social existente y plantearse la transformación del mismo mediante acciones diversificadas, bien calculadas y con la gradualidad adecuada para producir el menor malestar posible en los individuos, es algo que cuenta con muchos partidarios entre las gentes sensatas, entre eso que se llama el sentido común ilustrado. Por ello a casi todo el mundo le cae bien el Popper epistemólogo cuando habla, en éstos (o parecidos) términos, de modestia metodológica y de docta ignorancia. Todo juicio práctico es comparativo, y co- 
rren tiempos en los que no pocas de las personas que antes -cuando eran marxistas- querían cambiar el mundo postulan ahora que es mejor dejarnos transformar por él. La modestia, en estas cosas prácticas que acaban afectando a muchos prójimos, es siempre más sana que la doble negación.

Así que, de acuerdo con esto, la gente sensata dirá: si las llamadas ciencias sociales contemporáneas, con su complejo aparato matemático y su capacidad analítica, tienen muchas dificultades para explicar la acción colectiva de los humanos en condiciones de normalidad, ¿cómo atreverse a hacer predicciones en gran escala, que implican, para colmo, situaciones excepcionales? Y si ya es un exceso del orgullo y de la ambición de los humanos aspirar a hacer predicciones en gran escala tratándose del mundo social, ¿que decir de la pretensión de cambiar el mundo de base, que es precisamente lo que postula el marxismo?

Seguramente toda persona sensata y razonable que piense con un poco de calma sobre esto llegará a la conclusión de que una pretensión así, la aspiración a cambiar el mundo de base, que dice La Internacional - la aspiración a un orden radicalmente nuevo, a la emancipación del género humano-, es a la vez una enormidad y una temeridad. De hecho, hay mucha evidencia histórica en favor de tal conclusión. Las revoluciones se escapan de las manos de los revolucionarios (precisamente porque éstos no pueden dominar con el pensamiento todas las implicaciones y consecuencias que tienen actos complejos tan radicales); las revoluciones - se dice- devoran a sus hijos. Ya había ocurrido así en el caso de la revolución inglesa. Volvió a ocurrir en el caso de la revolución francesa. $Y$ ha ocurrido de nuevo en el caso de las revoluciones rusa y china, y, parcialmente, en los casos de la revolución cubana y vietnamita.

El número de personas sensatas y razonables aumenta de manera muy considerable cuando, con el paso del tiempo, el lado negro o negativo de las revoluciones resulta ya tan evidente para las nuevas generaciones, que sólo los ciegos pueden negarlo. Entonces el sentido común ilustrado y razonable se impone sobre 
cualquier otra consideración, echa a un lado toda duda y acaba adoptando esta filosofía: contra el orgullo y la soberbia de los revolucionarios del pasado y del presente, hay que ir pasito a pasito, uno por uno, y calculando bien cuál de las dos piernas conviene adelantar primero. Los ciegos que niegan, contra la evidencia, el lado oscuro y hasta tenebroso de las revoluciones que en el mundo han sido no serán tenidos en cuenta aquí. En cambio, vale la pena llamar la atención sobre un tipo de ceguera involuntaria tan extendido como reiterado a lo largo de la historia de la humanidad: el que produce en las buenas gentes la intensísima luz que brota de las revoluciones en marcha. Sin esta otra ceguera por deslumbramiento el número de las personas siempre sensatas y razonables permitiría formar en seguida una mayoría absoluta en cualquier circunstancia. Pero, al parecer, la historia de la humanidad es una tragedia y no nos ha sido dado a los más ser razonables y sensatos en todo momento. También el razonable y sensato teórico de la democracia modema, Alexis de Tocqueville, llamó la atención de sus contemporáneos, críticos de la revolución francesa, acerca de aquellas sombras del antiguo régimen que explican, al menos en parte, las luces cegadoras de las revoluciones en marcha.

\section{2}

Pero esto no es todo. Como escribiera Bertolt Brecht en un celebrado poema dialógico que lleva por título "Techo para una noche", justamente después de haber hecho justicia a la función de la caridad en los malos tiempos del paro masivo, del hambre y de la miseria: "No sueltes todavía el papel, tú que lo estás leyendo".

Siendo las cosas como se ha dicho, o sea, habiendo tanta evidencia histórica en contra de la pretensión de juntar explicación y transformación revolucionaria del mundo, y con un acuerdo tan general entre las personas sensatas acerca de la otra forma de actuación, lo difícil, lo verdaderamente difícil de explicar no debería ser la crisis del marxismo (enésima crisis, por cierto, calificada una vez más de definitiva), sino por qué motivo, a pesar de tanta evidencia y de tanta razón, tantos hombres en tantos lugares del mundo siguen planteándose (en la forma marxista o en otra) todavía la 
misma meta tantas veces fracasada o derrotada y tantas otras reinventada.

La explicación de la dificultad difícil -si se me permite la broma que, de paso, lleva el agua a mi molino- es que el sano sentido común, la evidencia histórica largamente interiorizada y la razón razonable de la mayoría de esa especie maravillosamente contradictoria que es la de los humanos no han logrado todavía encontrar la fórmula adecuada para terminar con el mal social, con la desigualdad social y con la injusticia.

Así, por ejemplo, el mercado, tal como lo conocemos, permite establecer algunas reglas en el juego económico consistente en ordenar recursos escasos, al que tan aficionado es el hermano lobo; pero no acaba con los monopolios, ni con la explotación de unos hombres por otros, ni reduce la desigualdad social, ni es capaz de fundar una sana relación entre el hombre y la naturaleza. Al contrario: la mano invisible que, según dicen, rige las leyes del mercado es demasiado visible a la hora de producir enormes beneficios para unos pocos, en detrimento de los más, y sólo se hace invisible de verdad a la hora de admitir responsabilidades por el expolio del medio ambiente.

En este sentido la que fue primera ministra de Noruega, Gro Harlen Brundtland ha escrito cosas luminosas que vienen a reforzar la desconfianza de muchos científicos sobre la capacidad que el llamado "mercado libre" tiene para hacer frente a los grandes problemas medioambientales de este final de siglo. "La conocida mano invisible de Adam Smith - concluye G.H. Brundtland en este punto- se creía que llevaba inconscientemente al interés privado a servir al bien común. En nuestro mundo moderno se siente la tentación de sugerir que hay un pie invisible que lleva al interés privado a emprenderla a patadas con el bien común". En tal contexto el reciente proyecto neosmithiano de privatizar algunas de las especies animales en peligro de extinción tiene que sonar como una trágica paradoja.

Por otra parte, Alexander King y Bertrand Schneider, autores del último informe al Club de Roma, La primera revolución mundial han llamado recientemente la atención acerca de las limutaciones del mercado polemizando incluso con quienes, eufóricamente, 
ven en él la solución a todos los problemas creados por el socialismo burocrático en la Europa del Este. "Los mecanismos del mercado escriben King y Schneider- no pueden habérselas por sí solos con problemas mundiales que requieren un enfoque estratégico o implican cuestiones de distribución. No pueden resolver por sí solos los problems relacionados con la energía, con el medio ambiente, con la investigación fundamental o con la equidad./.../ Además, las fuerzas del mercado pueden producir peligrosos efectos colaterales porque no están basadas en el interés general. La especulación financiera internacional constituye un ejemplo particularmente elocuente de los excesos de las fuerzas del mercado atenazadas por la obsesión del beneficio en cualquier circunstancia (blanqueo de dinero obtenido mediante el tráfico de drogas,ventas no autorizadas del armas, etc.)".

Suele ocurrir que los recien llegados a una ideología que consideran nueva se entregan a ella con la pasoón de los devotos. Así ha ocurrido en la antigua URSS y otros países de la Europa oriental en estos últimos años. Tal pasión oculta o disfraza los límites que otros, más precavidos o con más experiencia, pueden ver. King y Schneider, de cuya moderación política nadie puede tener dudas al terminar la lectura de La primera revolución mundial, se expresan así: "Es importante no considerar las fuerzas del mercado como el único agente necesario para la consecución de una vida mejor /... / y conocer bien sus límites. Para ello resulta indispensable no abandonar indiscriminadamente todos los ideales y conservar algunos de los aspectos más positivos del socialismo. En otro caso podría producirse una reacción adversa contra el capitalismo" (cit., pág. 580).

Algo parecido se puede decir de la democracia. La democracia es una buena cosa, qué duda cabe, en la medida en que reduce y controla tensiones políticas y contribuye a poner un bozal al histórico Leviatán; pero la democracia, esta democracia, la democracia realmente existente, no iguala las fortunas de todos en este mundo nuestro de hoy, que es, de hecho, una plétora miserable, el mejor de los mundos posibles, como dice sir Karl Popper, sólo que para unos cuantos y -aunque no lo diga el ilustre filosofoel peor de los infiernos para dos tercios de la humanidad. 
Esta democracia que conocemos sigue afirmando la igualdad de derechos de las mujeres y los varones, pero ignora que en el mundo aún mueren diariamente muchas más niñas y mujeres que niños y varones adultos porque hay, de hecho, discriminación en el trato de unas y de otros. En un interesantísimo ensayo publicado el año pasado en The New York Review of Books el economista Amartya Sen ha llamado la atención sobre un hecho al generalmente se presta poca atención, a saber: por qué si, según parece, la biología favorece a las mujeres después del nacimiento, en muchos lugares del mundo hay proporcionalmente más varones que hembras. La cifra de mujeres que faltan, de mujeres desaparecidas, se eleva a cien millones (la mayoría de ellas en Asia). "Una cifra ésta - comenta Amartya Sen-que habla silenciosamente de una historia terrible de desigualdad y de abandono, pues son la desigualdad y el abandono lo que conduce a una mayor mortalidad femenina". Discriminación entre los sexos, por tanto. Una discriminación que se mantiene en las fábricas, en los hogares, en los Parlamentos, en la política en general.

En los países que se autoproclaman democráticos la democracia se dice de muchas maneras, como el ser aristotélico. La democracia "por excelencia" es, como era de esperar, la del país "democrático por excelencia", es decir, la del más poderoso de los países desde el punto de vista militar y económico. En ese país la cantidad de dinero necesaria para que la gente del pueblo puede llegar a aspirar a gobernar es tal que nunca en su historia reciente ha podido llegar a ello nadie procedente del pueblo que no se haya hecho antes oligarca, o que esté más o menos directamente relacionado con el complejo militar-industrial. Algo parecido ocurre en los países democráticos europeos, los cuales en los últimos tiempos están, además, muy obnubilados con el modelo presidencialista norteamericano. A pesar de que en los EEUU de Norteamérica la mayoría de los ciudadanos se abstiene de participar en los procesos electorales (y no digamos en otras actividades políticas) y a pesar de la estructura manifiestamente oligárquica de los partidos y del espectáculo-representación electoral, se dice y se repite que este país es "la democracia por excelencia". 
Siendo tal el rasero para juzgar a las otras democracias en el mundo actual, se comprende que los requisitos exigidos para adoptar este nombre no sean muy fuertes, aunque, eso sí, dichos requisitos pueden ser impuestos por instituciones que sólo los cumplen a medias. En la práctica suele bastar con un requisito real y otro simulado. El requisito real es este: libertad de mercado, o sea, posibilidad de comercio abierto para la ampliación de los negocios. Con este requisito ha bastado para considerar "democracias de verdad" a las antiguas "democracias populares" del este de Europa. Tal es el caso de países como Hungría (donde el índice de abstención de los ciudadanos en los procesos electorales ha sido tan notable como la capacidad de algunos de sus dirigentes para cambiar de camisa, pero donde el "mercado libre" ha dejado en manos de las empresas transnacionales buena parte de los medios de comunicación) y de Polonia (donde Walesa está amenazando cada dos días con disolver el Parlamento si los miembros del mismo no se atienen a sus deseos integristas, pero donde el "mercado libre" ha dado lugar a la paradoja de que una nación que tanto ha luchado por la soberanía pierda de hecho esta soberanía a manos de la industria y las finanzas transnacionales).

Luego está el requisito, por así decirlo, "simulado": parlamento y partidos; requisito éste que, de hecho, suele quedar reducido a la legalización de otro partido distinto del de los que mandan o mandaban, puesto que algún tipo de parlamento (cortes, duma o institución equivalente) suele haber ya en todas partes, y sería de mal gusto exigir la existencia de más partidos cuando en la "democracia por excelencia" y en la "democracia" que sigue en el ranking a la "democracia por excelencia" no hay más que dos partidos (o dos y medio). En realidad la teoría operante de la democracia contemporánea, tal como se aplica en el país "democrático por excelencia", da muy poca importancia ya a la actividad parlamentaria y cada vez se limita más al simple reconocimiento de la existencia de una oposición política organizada dentro de un orden y de un marco que vienen definidos precisamente por la aceptación, por parte de la oposición, de la "libertad de mercado". Así resulta que la llamada "oposición" no se opone de hecho a nada serio en el sistema capitalista establecido; actúa por lo gene- 
ral como mero personal de recambio de una clase política que se supone ha de compartir un mismo concepto de subordinación de lo político a lo económico.

La condición o exigencia "simulada", precisamente por serlo, se puede negociar en función de otras circunstancias específicas de cada país, pero siempre dependientes del vínculo que se tiene con los EEUU de Norteamérica, o, también, de la situación geopolítica y de si es una potencia nuclear o no: Así, por ejemplo, la exigencia de que haya partidos y elecciones libremente convocadas para la representación parlamentaria será una condición fuerte si se trata de un país considerado por el Imperio como adversario en sentido propio. De esta manera Cuba no será considerada "democrática" si no cumple el requisito "simulado" en sentido fuerte; lo mismo puede decirse para la Nicaragua gobernada por los sandinistas, como se vió hace unos años. La antigua URSS es, naturalmente, un caso aparte. La acumulación de armas nucleares en su territorio debilita ligeramente el requisito fuerte, pero el tipo de propaganda hecha durante décadas en EEUU obliga ahora a guardar un poco más las formas (aunque los acontecimientos relacionados con la independencia de Ucrania prueban que a la "democracia por excelencia" siguen preocupándole más el lugar en que queden las armas nucleares de la antigua URSS y su control futuro que el respeto a la legalidad democrática propiamente dicha). En cualquier caso, en lo concerniente a la situación de la URSS hay división de opiniones en el centro del Imperio, motivadas por la existencia de intereses distintos en los bloques económicos dominantes: unos querrían que se cumpliera con los dos requisitos y otros estarían dispuestos a aceptar que se cumpliera sólo el "simulado".

La traducción literal de esta división de opiniones al lenguaje político directo es: unos poderosos piensan que basta con el "mercado libre" para que que allí haya democracia y otros poderosos creen que convendría que, además, hubiera "elecciones libres". En cambio, suele hacerse la vista gorda en cuanto a los procesos de transición a la democracia que tienen lugar en países en los que hay o ha habido una dictadura amiga. Las reacciones de los dirigentes norteamerianos al intento de golpe militar en la España de 1982 fueron sintomáticas. Y la misma ambigüedad calculada se da en casos como el de Turquía. 
Que esto es realmente así, que la utilización de dos raseros para medir el grado de democracia de cada país es un hecho corriente en estos tiempos, puede argumentarse con más detalle a partir de lo ocurrido en sitios tan distintos como Chile e Italia desde 1972 en adelante. Justamente aquellas democracias en las que existía desde años atrás una activa y amplia participación política de las gentes y donde esta participación coincidía, además, con la existencia de fuertes partidos políticos de la izquierda (digna todavía de ese nombre) y de sindicatos de clase que cumplían cun los principios establecidos en sus programas, fueron considerados por la "democracia por excelencia" y por la Comisión Trilateral entonces naciente como "democracias ingobernables". Muchas personas recordarán la injerencia de las multinacionales con sede en los EEUU de Norteamérica en los meses inmediatamente anteriores al golpe militar de Pinochet que terminó con la democracia en Chile. (Por cierto: nadie pidió entonces en Europa la disolución de la democracia cristiana italiana o alemana, a pesar de la evidente complacencia de su homónimo chileno con el golpe de Pinochet). Transcurrieron los años, el general, su ejército y su policía cumplieron su función con la ayuda de los economistas neoliberales de Chicago (que identifican, éstos sin mayores distingos democracia con libre mercado) los democristianos cambiaron a un Frei por otro Frei, se pactó una solución de compromiso con Pinochet y se consideró que con ello ya estaba restablecida la democracia en Chile.

Se conocía menos, en cambio, la injerencia de la OTAN (el "puntal de la democracia europea", como se dijo durante el debate que tuvo lugar en España) en la "ingobernable" Italia. Ha habido que esperar a la transmutación del partido comunista italiano, en 1990, para que saliera a la luz lo que representó en la Italia de aquellos años la red Gladio, cuya vinculación a los servicios secretos del Estado italiano y a la OTAN era conocida y alentada por prominentes miembros de la democracia cristiana que hoy tienen el cinismo de presentar la cosa como una contribución particular, y ante litteram, a la consecución de aquello (el final del comunismo) en que todos parecen estar de acuerdo. De nuevo, en la democracia realmente existente el fin justifica los medios. 
Pero, ¿y el fín? ¿qué es el fín? Hace ya tiempo que la teoría política neomaquiaveliana (Pareto, Mosca, Burnham, Michels) puso de manifiesto que los regímenes democrático-constitucionales, a pesar de las instituciones parlamentarias y de la representación, indirecta, de la voluntad popular que las caracteriza, son en el fondo oligarquías. Con independencia de que en ella quede formalmente garantizada la soberanía popular a través de la electividad de los representantes del pueblo, la tendencia hacia formas oligárquicas viene determinada aquí - a diferencia de lo que ocurre en otros regímenes- por el dominio del dinero. La mercantilización constante del proceso político hace de las democracias constitucionales oligarquías plutocráticas en las que se reproduce la desigualdad social por otras vías diferentes de la limitación del sufragio. Según esto, también las democracias parlamentarias trabajan para el pueblo pero sin el pueblo, puesto que no es el pueblo quien gobierna en ellas.

El pensamiento político liberal contemporáneo, conservador o no, suele aceptar esta caracterización neomaquiveliana de la oligarquización de las democracias como una apreciación realista, adecuada a los hechos principales observables en la mayoría de países con régimen democrático constitucional. Pero, por otra parte, el liberalismo renovado - que se da cuenta de la parcial coincidencia de esta crítica neomaquiaveliana de la democracia con la crítica marxista y libertaria de la misma - se afana luego en desplazar los acentos hacia otra consideración. Compara ese proceso de oligarquización de las democracias con lo que ocurre o ha ocurrido en los regímenes autoritarios de diverso signo. Pues - se aduce en este contexto- también éstos son oligárquicos, también éstos están dominados por minorías, y en mayor medida, pero con la diferencia, desfavorable a ellos, de que no hay ni puede haber control ni renovación de las oligarquías mismas, de los que mandan, del privilegio del mandar.

Vale la pena, sin embargo, hacer el ejercicio mental consistente en reflexionar acerca de dos cosas juntas: la superioridad moral de la democracia representativa sobre el autoritarismo y la inevitable tendencia hacia la oligarquización plutocrática. Y reflexionar sobre ellas en un contexto histórico completamente cambiado respecto 
de la situación que siguió a la segunda guerra mundial. Hay que reconocer entonces que el descubrimiento neomaquiaveliano, generalmente aceptado hoy por todas las corrientes del pensamiento político contemporáneo, adquiere una dimensión nueva: el inquietante hecho del caracter oligárquico de las democracias resalta mucho más cuando ya no existe otro bloque en el que ver la cara del enemigo, sino sólo espejos en los que mirarse. $\mathrm{El}$ carácter oligárquico y plutocrático de las democracias constitucionales de representación indirecta salta a la vista como una deformidad, esto es, como una demediación de la democracia propiamente dicha, cuando se la mira directamente a la cara, sin comparaciones odiosas que, en el fondo (para qué vamos a engañarnos), la disfrazaban y embellecían mucho.

\section{7}

De la argumentación neomaquiaveliana no sólo sale la descripción veraz de la limitación interna (económica, principalmente) de las democracias constitucionales. También puede deducirse de ella un esquema interpretativo de la historia reciente de las democracias que seguramente no carece de interés para todas aquellas personas que están convencidas de que la democracia es siempre un proceso en construcción, cuyo éxito y profundización depende muy directamente de la presión de los de abajo y de la vigilancia de estos mismos justamente frente a las tendencias oligárquicas y plutocráticas. Este esquema permite establecer una tendencia histórica, según la cual a medida que se extiende el sufragio por abajo, esto es, a medida que la igualdad jurídica formal alcanza techos más elevados en los países democráticos, aumenta la presión de los intereses creados por el dinero para corregir los desplazamientos y cambios que puedan llegar a afectar a los antiguos privilegios. Los poderosos, las clases dominantes, han acudido históricamente a soluciones varias en función de las formas que ha ido tomado la lucha por la hegemonía en las sociedades democráticas.

La extensión del sufragio por abajo se corrigió, o se complementó, con las leyes contra los socialistas. La presión por abajo en favor de la ampliación del sufragio y de la igualdad produjo exclamaciones célebres por parte de los privilegiados y de los políti- 
cos conservadores (con consecuencias nefastas para las clases sociales ascendentes), como aquella de que la legalidad nos mata.

Pero a medida que, en la cultura euroamericana, se extiende la convicción de que el problema de la hegemonía tiene que resolverse por vía pacífica y respetando el pluralismo político parlamentario, la legalidad parece a veces haber dejado de matar privilegiados. (Aunque tampoco conviene hacerse demasiadas ilusiones a este respecto: ni siquiera en esto la historia es lineal y simplemente progresiva). Por lo general ahora se trata de interpretar convenientemente esta legalidad.

$Y$ también de corregir - cuando se considera necesario- el valor de un voto con el valor (mucho mayor) mercantil del dinero. Esta parece una explicación apropiada de lo que pasó en Italia cuando Enrico Berlinguer, que seguramente habrá sido el último político liberal consecuente de los últimos tiempos, propuso el compromiso histórico, con lo que se llegó a un paso de que el partido comunista se convirtiera allí en la fuerza política mayoritaria. "La legalidad nos mata", hubiera sido una frase muy fuerte para ser pronunciada en público en la Italia de 1977. Así que se dijo, en tono más comedido, pero igualmente decisivo: "Hay democracias que son ingobernables".

En cualquier caso, la desestabilización de las democracias constitucionales por las oligarquías del dinero se ha hecho mucho más fuerte -contra lo que se piensa a menudo ingenuamente- en la década de los 80 , a medida que se extendía el americanismo a todo el mundo. (Formalmente, usted tiene garantizada la misma posibilidad de voto que Agnelli o que Mario Conde, pero a medida que las campañas electorales se hacen más costosas, usted, que tiene formalmente las mismas posibilidades de decir lo que piensa o lo que siente que Mario Conde o que Agnelli sólo tiene los medios reales para decírselo a su pariente más próximo o al vecino de al lado.) Poco a poco la consecuencia de tal desigualdad, que empieza a manifestarse a través del dinero, y continúa manifestándose a través de los medios de comunicación de masas (en los que también hay que pagar), profundiza el proceso de oligarquiza- 
ción: el pobre, el pequeño, no tiene dinero para campañas electorales y cuando en el lugar en que los poderosos ponen el dinero él pone su trabajo voluntario, entonces los poderosos suelen sacar una ley electoral que favorece directamente a los grandes en todos los ámbitos (en el reparto de los dineros públicos, en el reparto de los espacios en televisión, en el reparto de los restos electorales,etc.).

El sida de la democracia representativa demediada se produce cuando la oligarquía plutocrática logra que los competidores políticos lleguen a creerse que ellos también pueden hacerlo igual porque la ley es igual para todos, que ellos, los pobres, los pequeños, pueden realmente competir jugando en el campo del adversario y con la baraja marcada por el adversario. Bajo este engaño han muerto en Europa un montón de ideas políticas excelentes defendidas por políticos e intelectuales moralmente intachables, e inteligentes en todo lo demás. Estas buenas gentes sólo cometieron un error: el de creer que ya eran mayores y lo suficientemente fuertes para dejar de oponer el trabajo voluntario de los militantes que creen en los ideales por los que luchan a los dineros de las oligarquías, pasando a competir con éstas en las visitas a banqueros, en la obtención de créditos, en la creación de empresas de cuyos beneficios obtener medios indirectos de financiación de las campañas políticas, etc. El querer hacer como los otros sin poder hacerlo de verdad, el caer en la ilusión de las subvenciones estatales y privadas graciosas (en el engaño de los dineros estatales o privados se dan a fondo perdido) ha sido el primero de los pecados veniales que acabaron conduciendo a la vieja izquierda europea a la identificación con el otro. Es así como la izquierda europea ha pasado a ser, de hecho, la mano izquierda de la derecha. Cuando ya no hay otro programa, ni otra política económica que oponer, ni otra forma de militancia, ni otra forma de ver el mundo, ni otra forma de comportarse, entonces sólo queda la diferenciación individual por el dinero que se posee. En cierto modo, eso es la muerte de la política en la acepción que la palabra política ha tenido desde los años veinte de este siglo, como intervención activa de las grandes masas en la cosa pública. 
Hay tres falacias muy recurrentes en torno a la democracia realmente existente. La primera consiste en reducir la democracia a la suma de elecciones+partidos+parlamento. La segunda se expresa en la afirmación, tantas veces repetida, de que la democracia es cara pero tiene que ser aceptada así porque, a pesar de ello, es el sistema mejor, o el menos malo de los posibles. Y la tercera falacia consiste en afirmar que democracia no hay más que una y que, por tanto, cualquier crítica que se haga de la democracia realmente existente es negativa y contraproducente porque puede servir de cobertura para maniobras antidemocráticas.

\section{0}

Pues bien: cuando la gente se da cuenta de estas cosas (de la insuficiencia del mercado, de los límites de la democracia mercantil y oligárquica) deja de ser razonable en el sentido anteriormente dicho y apela a otra razón. Si, además, son tiempos de vacas flacas, y los hombres y las mujeres razonables moran en países en los que mueren miles de niños al día, en los que se esclaviza a otros, se prostituye a muchos y se tortura al que protesta, entonces ( $y$ no es ésta la única situación de injusticia posible en el mundo de hoy) la anterior evidencia histórica se hace menos evidente y el gradualismo propuesto para las actuaciones menos razonable. ¿Se puede acaso graduar la satisfacción de las necesidades básicas, elementales, cuando la gente está a un tris de morirse de hambre? Y ¿por qué sigue conmoviendo y emocionando tanto a las buenas gentes, igual en el Norte que en el Sur, el espíritu de la rebelión, las viejas historias de los hombres y de las mujeres que se alzaron y se alzan contra la desigualdad intolerable? No se puede negar a Marx y a algunos marxistas (a Rosa Luxemburg, a Antonio Gramsci, a Georg Lukács, a Karl Korsch, por no hablar de Brecht y de Benjamin, tan lúcidos en su diagnóstico), el haber dicho unas cuantas cosas serias sobre esta seria cosa que es la actitud de los hombres y de las mujeres ante la lucha de clases.

Así pues, lo que es evidencia histórica y conclusión razonable para unos acaba resultando un hiriente insulto para otros. Esto se debe a que, nos guste o no, existe en el Planeta algo así como eso 
a lo que se ha llamado - a veces también con un poco de petulancia, todo hay que decirlo- lucha de clases a nivel mundial. Cuando Marx escribió el Manifiesto comunista, el mundo (incluso para un alemán que se quería internacionalista) era Europa y poco más. Ahora el mundo son los cinco continentes: vemos en directo $-y$ hasta podríamos vivirlo, si además de ser razonables nos hubiera sido dada la gracia de los sentimientos humanitarios y de la coherencia entre el decir y el hacer- el hambre, la tortura, la desigualdad social, la miseria material y psíquica en Africa, en Asia, en América Latina y en los suburbios de las principales ciudades de Europa, de los EEUU de Norteamérica, del Japón.

\section{1}

No pocas personas sensatas y razonables del Norte se hacen la ilusión de que estos males del Sur nada tienen que ver con nosotros, con nuestro mercado, con nuestra democracia mercantil. $Y$ concluyen, desde esa ilusión, que nuestro mercado y nuestra democracia mercantil no sólo no son responsables de tanta miseria y de tanta muerte, sino que evitan la miseria y la muerte allí donde se instalan. Pero no hace falta ser historiadores, basta con fijarse un poco más en las tragedias del mundo que en los conceptos de democracia y mercado ahistóricamente formulados, para darse cuenta de que las rapiñas de nuestros antepasados colonizadores, las constricciones impuestas por el Banco Mundial y los beneficios de las multinacionales con sede en EEUU, Japón y la CEE, tienen tanta relación con la miseria del Sur y con su crisis ecológica como la explosión demográfica que se está viviendo en aquellos países.

La desigualdad social existente en la Europa del XIX hizo nacer el marxismo en Europa. La tremenda desigualdad mundial existente ahora hará nacer otro intento de juntar la explicación del mal social con la exigencia de cambiar el mundo de base.

El intrumental científico y técnico para eso empieza a estar a punto. ¿Qué nombre se pondrá al nuevo intento? ¿Se seguirá llamando a ésto marxismo? Nuestros jóvenes llaman insumisión y desobediencia civil al espíritu de la rebelión que está en los prolegómenos de la nueva tentativa; los campesinos latinoamericanos llaman a la nueva cosa (híbrido de marxismo crítico y de 
cristianismo inspirado en el Sermón de la Montaña) teología de la liberación. Nombres tal vez parciales y, sin duda, prematuros. Pero lo que importa es el concepto, lo que importa es que también ahora hay argumentos a favor de un punto de vista que no sea sólo y dogmáticamente liberal.

Liberales lo somos todos de salida (al menos aquí, en Europa). Marx también lo era de joven.// Wallerstein replantea el viejo debate sobre los dos Marx en unos términos que me parecen muy apropiados en la situación de ahora. Contrapone a un Marx que se rebela contra el pensamiento liberal burgués (con su antropología fundada en el concepto de naturaleza humana, sus imperativos categóricos kantianos, su confianza en el lento pero inevitable mejoramiento de la condición humana y su preocupación por el individuo a la búsqueda de la libertad) a otro Marx que aceptó el universalismo al aceptar la idea de una inevitable marcha de la historia hacia el progreso, un segundo Marx más aceptable para los liberales. Wallerstein prefiere el Marx "fastidioso" de la polarización social, el Marx que no tuvo dificultad en mostrar cómo los liberales abandonaban sus principios cada vez que veían amenazado el propio orden social, el Marx que recordó a los liberales sus propias palabras, que llevó la lógica del liberalismo a sus consecuencias últimas y que, con ello, hizo digerir a los liberales la misma medicina que ellos prescribieron a los otros: más libertad, más igualdad, más fratemidad. Luego, con el tiempo y los años, unos liberales prefieren el autoritarismo del déspota bondadoso (como los liberales de la Trilateral y no pocos de los científicos liberales que se han planteado en serio la interrelación de los problemas económico-sociales con los problemas ecológicos de este final de siglo) y otros liberales preferimos el igualitarismo social radical, la superación de la forma actual, capitalista, de la división social fija del trabajo. ¿O tendrán que seguir haciendo siempre los mismos, y los hijos de los mismos, las tareas de mantenimiento y limpieza de nuestra pocilga?

Es posible que esta diferencia de criterio entre sólo liberales y algo más que liberales (libertarios, socialistas, comunistas) no exista ya cuando la llamada democracia del mercado haya logrado dar de comer a los hambrientos y de beber a los sedientos del mundo entero, de nuestro mundo. Mientras tanto, mientras haya 
en el mundo más desigualdades e injusticias que las que está dispuesta a admitir la filosofía liberal dominante, es de esperar que los desposeidos, además de interpretar este mundo, sigan pensando en la necesidad de cambiarlo de base, de raíz. 